\title{
ON THE STOKES EQUATIONS WITH THE NAVIER-TYPE BOUNDARY CONDITIONS
}

\author{
Cherif Amrouche And Nour El Houda Seloula
}

Abstract. In a possibly multiply-connected three dimensional bounded domain, we prove in the $L^{p}$ theory the existence and uniqueness of vector potentials, associated with a divergence-free function and satisfying non homogeneous boundary conditions. Furthermore, we consider the stationary Stokes equations with nonstandard boundary conditions of the form $\boldsymbol{u} \cdot \boldsymbol{n}=g$ and $\operatorname{curl} \boldsymbol{u} \times \boldsymbol{n}=\boldsymbol{h} \times \boldsymbol{n}$ on the boundary $\Gamma$. We prove the existence and uniqueness of weak, strong and very weak solutions. Our proofs are mainly based on Inf - Sup conditions.

Mathematics subject classification (2010): 35J50, 35J57.

Keywords and phrases: vector potentials, $L^{p}$-theory, Navier boundary conditions, Stokes equations, inf-sup condition, Sobolev inequality.

\section{REFERENCES}

[1] C. Amrouche, C. Bernardi, M. Dauge, V. Girault, Vector potentials in three-dimensional nonsmooth domains, Math. Meth. Applied. Sc., 21 (1998), 823-864.

[2] C. Amrouche, P. G. Ciarlet, P. Ciarlet, JR, Vector and scalar potentials, Poincare's theorem and Korn's inequality, C. R. Math. Acad. Sci, Paris, 345, 11 (2008), 603-608.

[3] C. Amrouche, V. Girault, Decomposition of vector space and application to the Stokes problem in arbitrary dimension, Czechoslovak Math. J., 119, 44 (1994), 109-140.

[4] C. Amrouche, M. A. RodrígueZ-Bellido, Stokes, Oseen and Navier-Stokes equations with singular data, Arch. Rational. Mech. Anal., 199 (2011), 597-651.

[5] C. Amrouche, N. Seloula, $L^{p}$-theory for vector potentials and Sobolev's inequalities for vector fields. Application to the Stokes problem's with pressure boundary conditions. To appear in Math. Models Methods Appl. Sci.

[6] G.S. BeAVERS, D.D. JosePh, Boundary conditions at a naturally permeable wall, J. Fluid Mech., 30 (1967), 197-207.

[7] H. BeIRÃO DA VeIgA, F. CRISPO, Sharp inviscid limit results under Navier type boundary conditions. An $L^{p}$ theory, J. Math. Fluid Mech., 12 (2010), 397-411.

[8] J. M. Bernard, Non-standard Stokes and Navier-Stokes problem: existence and regularity in stationary case, Math. Meth. Appl. Sci, 25 (2002), 627-661.

[9] J. M. BERNARD, Time-dependent Stokes and Navier-Stokes problems with boundary conditions involving pressure, existence and regularity, Nonlinear Anal. Real World Appl., 4, 5 (2003), 805-839.

[10] L. C. BERSELLI, An elementary approach to the 3D Navier-Stokes equations with Navier boundary conditions: Existence and uniqueness of various classes of solutions in the flat boundary case, Discrete Contin. Dynam. Systems Series S., 3 (2010), 199-219.

[11] J. Bolik, W. VON. WAHL, Estimating $\nabla u$ in terms of $\operatorname{div} u$, curl either $v, u$ and $(v \times u)$ and the topology, Math. Meth. Appl. Sci., 20 (1997), 737-744.

[12] J. H. BRAmBlE AND P. LEE. On variational formulation for the Stokes equations with nonstandard boundary conditions, RAIRO Modél. Math. Anal. Numér., 28 (1994), 903-919.

[13] C. ConCA, Approximation de quelques problèmes de type Stokes par une méthode d'éléments finis mixtes, Numer. Math., 45 (1984), 75-91.

[14] C. Conca, F. Murat, O. Pironneau, The Stokes and Navier-Stokes equations with boundary conditions involving the pressure, Japan. J. Math.,20 (1994), 263-318. 
[15] V. Girault And P.-A. Raviart, Finite Element Methods for the Navier-Stokes Equations, Theory and Algorithms, Springer, Berling, 1986.

[16] H. Kozono, T. Yanagisawa, $L^{r}$-variational inequality for vector fields and the Helmholtz-Weyl decomposition in bounded domains, Indiana Univ. Math. J., 58, 4 (2009), 1853-1920.

[17] D. Mitrea, M. Mitrea, J. Pipher, Vector potential theory on nonsmooth domains in $\mathbb{R}^{3}$ and applications to electromagnetic scattering, J. Fourier Analysis and Application, 3, 2 (1997), 131-192.

[18] M. Mitrea, S. Monniaux, On the analyticity of the semigroup generated by the Stokes operator with Neumann-type boundary conditions on Lipschitz subdomains of riemannian manifolds, Transactions of the American Mathematical Society, 361, 6 (2009), 3125-3157.

[19] C.L.M.H. NAVIER, Sur les lois de l'équilibre et du mouvement des corps élastiques, Mem. Acad. R. Sci. Inst., 6, France, 1827.

[20] N. Seloula, Mathematical analysis and numerical approximations of the Stokes and the NavierStokes equations with non standard boundary conditions, $\mathrm{PhD}$ Thesis, Université de Pau et des Pays de l'Adour, 2010.

[21] J. SerRin, Mathematical principles of classical fluid mechanics, Handbuch der Physik, SpringerVerlag, 1959.

[22] V. A. Solonnikov, V. E. Scadilov, A certain boundary value problem for the stationary system of Navier-Stokes equations, (Russian) Trudy Mat. Inst. Steklov., (1973), 196-210.

[23] W. Von. Wahl, Estimating $\nabla u$ by $\operatorname{div} u$, $\operatorname{curl} u$, Math. Meth. Appl. Sci., 15 (1992), 123-143. 